\title{
Occurrence and Influencing Factors of Antibiotics and Antibiotic Resistance Genes in Sediments of the Largest Multi-habitat Lakes in Northern China
}

\author{
Tongfei Wang \\ China University of Geosciences \\ Weijun Zhang \\ China University of Geosciences \\ Meiyi Zhang \\ Chinese Academy of Sciences \\ Guiying Liao ( $\square$ liaogy@cug.edu.cn ) \\ China University of Geosciences

\section{Liqing Li} \\ China University of Geosciences

\section{Dongsheng Wang} \\ Chinese Academy of Sciences
}

\section{Research Article}

Keywords: Baiyangdian Lake, Sediment, Antibiotic, Antibiotic resistance gene, Influencing factor

Posted Date: January 7th, 2022

DOI: https://doi.org/10.21203/rs.3.rs-1004244/v1

License: (c) (i) This work is licensed under a Creative Commons Attribution 4.0 International License. Read Full License 


\section{Abstract}

Baiyangdian Lake is a typical and largest multi-habitat lake in the North plain of China. To understand the generation and transmission of antibiotics resistance genes (ARGs) in multi-habitat lakes, the contents of nutrients (TC, TOC, TN, TP and TS), heavy metals ( $\mathrm{Zn}, \mathrm{Cr}, \mathrm{Ni}, \mathrm{Cu}, \mathrm{Pb}, \mathrm{As}, \mathrm{Cd}$ and $\mathrm{Hg}$ ), 22 antibiotics, 16SrRNA(16S), Class I integron (intl1) and 20 ARGs were determined. Samples were taken from the Fuhe river, river estuaries, reed marshes, living area, fish poods and open water of Baiyangdian Lake. The results showed that quinolones (QNs) were the main pollutants, and the content range was ND-104.94 ng/g. Thereinto, aac (6') -IB, blaTEM-1, ermF, qnrA, qnrD, tetG, sul1, sul2 and tetM were detected in $100 \%$. The absolute abundance of sul1 was the highest $\left(5.25 \times 10^{5} \mathrm{copies} / \mathrm{g}-6.21 \times 10^{7} \mathrm{copies} / \mathrm{g}\right)$, which was the dominant ARGs. In these different habitats, the abundance of antibiotics and ARGs in river estuary was the highest, and that in reed marshes was the lowest. There was a significant positive correlation between the abundance of heavy metals $(\mathrm{Cu}, \mathrm{Pb}, \mathrm{Zn}, \mathrm{Ni}, \mathrm{Cd}, \mathrm{Hg})$ and the absolute abundance of $11 \mathrm{ARGs}(\mathrm{P}<0.01)$. Redundancy analysis showed that $\mathrm{Cu}, \mathrm{Zn}$, intl1, TP and macrolides (MLs) were the important factors affecting the distribution of ARGs. Our findings provides a more likely driving and influencing factor for the transmission of ARGs in lakes with complex and diverse habitats.

\section{Introduction}

Antibiotics is widely used to treat the infectious diseases of human and animal by killing or inhibiting bacterial growth (Zhu et al., 2020). Recent surveys show that global antibiotic consumption is estimated to be 84 billion defined daily doses in 2030, double the amount in 2015 (Klein et al., 2018). However, except to a small part absorbed and metabolized by the human body, 30-90 \% of the antibiotic will enter the soil and aquatic environment through the urine and feces of human and animal in the form of original medicine (Liu et al., 2019; Muhammad et al.,2020). Antibiotic misuse, poor stewardship and unintentionally discharged into the environment pose a huge threat to the ecosystem and human health (Kümmerer, 2009). Over the past few decades, antibiotics have been found in environmental media such as wastewater treatment plants (WWTP) (Zhang et al., 2021; Cheng et al., 2014b), rivers (Zhang et al., 2020b), oceans (Du et al., 2019), sediments (Chen et al., 2019b; Li et al., 2018a), soil (Quaik et al., 2019), organism (Zhao et al., 2015), air (Li et al., 2018b), due to its pseudo-persistence and low biodegradability (Gulkowska et al., 2008; Chen et al., 2018). The most worrying thing is that bacteria in water and sediment are exposed to the water environment with the accumulation of antibiotics for a long time, and they are stimulated to produce ARGs (Larson et al., 2007; Luo et al., 2010; Zheng et al., 2018).

Once the bacteria mutate or acquire ARGs, they may exist in large numbers in the environment persistently, and can accelerate or even induce the production and spread of antibiotic resistance genes through horizontal gene transfer (Zhu et al., 2013; Gillings et al., 2014). Seriously, ARGs can enter the human body through the food chain, leading to the weakened or ineffective antibiotic drugs (Reichert et al., 2021). ARGs, as a new type of pollutant, has the characteristics of strong persistence, wide range of diffusion and strong fluidity, which may pose potential risks to global human health (Amarasiri et al., 2020). 
In recent years, $A R G s$ in aquatic environments have been frequently detected in different areas, such as the USA (Pruden et al., 2012), European countries (Knapp et al., 2010; Czekalski et al., 2015; Paulus et al., 2019), Australia (Han et al., 2016), Korean (Kim et al., 2017), Japan (Nguyen et al., 2019), China (Zhang et al., 2015), even in polar environments (Mccann et al., 2019). In particular, the pollution of ARGs in rivers or lakes in China may be more extensive and serious. For instance, the absolute abundance of sul1, tetA and tetE genes were found in seven urban rivers in Beijing (Xu et al., 2016); sulfonamide resistance genes (sul1 and sul2) were widely distributed in the water of Fuxian Lake, the deepest freshwater lake in China(Zhao et al.,2020); 321 ARGs were detected in the sediments of Tai Lake, and its abundance and risk are higher than other global lakes (Chen et al.,2019a); 15 lakes from the Yangtze river were suffered heavy sul and tet ARGs pollution (Yang et al.,2017). However, previous work was focus on the distribution of antibiotics and ARGs in the sediments of lakes in a single habitat, and till now, their correlation or traceability has not come to a uniform conclusion in detail, especially for the lakes with different habitats. Therefore, it is extremely urgent to carry out researches to explain autochthonous antibiotics and ARGs diversity as well as to find the possible driving factors of ARG in local sediments in different habitats.

Baiyangdian Lake is an important water resource located in the Xiongan New Area of China, which is known as "the lung of North China". And it is the largest multi-habitat lake in the North plain of China. The lake has a unique structure consisting of 143 lakes, each of them is separated and connected with each other, which is quite different from the aquatic environment of inland lakes in the south and artificial reservoirs in the north in China (Chen et al., 2021). Before 2017, industrial wastewater, especially the wastewater of paper mill from Baoding City, was the main source of pollution, and human activities directly or indirectly affected the aquatic environment of Baiyangdian Lake (Zerizghi et al., 2020). In the previous study, with the increase in the discharge of antibiotics and other pollutants (such as heavy metals, persistent organic pollutants) into Baiyangdian Lake, the rapid and extensive growth of ARG has been accelerated (Cheng et al., 2014; Ji et al., 2020). Thus, most studies have demonstrated the occurrence of antibiotics in rivers or lakes, while the research regarding on the occurrence and relationship of antibiotics and ARGs simultaneously in different habitats of Baiyangdian Lake is relatively few. In this study, we describe the occurrence of antibiotics and ARGs in sediments of Baiyangdian Lake, aiming to track the effect of the different habitats including Fuhe river, reed marshes, open water, living areas, fish poods and river estuary. It provides a more likely driving and influencing factor for the transmission of ARGs in lakes with complex and diverse habitats. Sediment samples were collected to determine correlations between ARGs, antibiotics, heavy metals and other environmental factors.

\section{Materials And Methods}

\subsection{Chemicals and standards}

According to the classification of sulfonamides(SAs), tetracyclines(TCs), QNs and MLs, a total of 22 antibiotics were selected, including sulfamerazine (SMR), sulfadimidine (SMZ), sulfadiazine (SDZ), sulfapyridine (SPD), sulfamethoxypyridazine(SMP), sulfaquinoxaline (SQX), sulfamethoxazole (SMX), sulfamethoxazole (STZ), ciprofloxacin (CIP), enrofloxacin (ENR), lomefloxacin (LOM), norfloxacin (NOR), sparfloxacin (SPA), ofloxacin (OFL), tetracycline (TC), doxycycline (DOC), oxytetracycline (OTC), 
chlortetracycline (CTC), clarithromycin (CTM), azithromycin (AZM), dehydration erythromycin $\left(E R M-\mathrm{H}_{2} \mathrm{O}\right)$ and roxithromycin (RTM) were purchased from the laboratory of Dr. Ehrenstorfer (Augsburg, Germany). SMZ$\mathrm{d}_{4}$ was used as an internal standard and purchased from ANPEL Laboratory Technologies (Shanghai, China). All chemicals or solvents are at least chromatographically pure, both the standard and the internal standard with a concentration of $1 \mathrm{mg} / \mathrm{L}$ are dissolved in methanol, and stored in amber glass vials at $-20^{\circ} \mathrm{C}$ for subsequent analysis.

\subsection{Sampling site and sample collection}

Baiyangdian Lake is located in the middle of Hebei province, with a surface area of $366 \mathrm{~km}^{2}$ and an average depth of approximately 2-5 m (Yang et al., 2020). Surface sediments from six different habitats in Baiyangdian Lake were collected. From August to September 2020, 10 sediment samples in the Nanliuzhuang and Caiputai areas of Baiyangdian were determined (Fig. 1, Table S1). The characteristics of six habitats were as following: the Fuhe river (S1), the river estuaries (S2), the reed marshes (S3 and S9), the living area (S4), the fish poods (S5-S8), and the open water(S10). Specifically, there are four different types of fishing poods habitats: S5 is the former fishing ground that has been drained into the river, S6 is the dredging, S7 is the successful in-situ bioremediation, and S8 is the failure of bioremediation. Meanwhile, the reed marshes S3 is close to the river estuaries (S2), while S9 is in the center of large reed marshes area. Then 3 parallel samples around the same sampling point were taken, mixed evenly and placed in a glass bottle, and transported to the laboratory for processing within $24 \mathrm{~h}$.

\subsection{Quantification of antibiotics}

The sediment was pretreated using a multiphase solid phase extraction (SPE) system (supelco, USA) as previously described (Chen et al., 2014). In brief, $3 \mathrm{~g}$ of the sediment sample was accurately added in a 50 $\mathrm{mL}$ centrifuge tube, and the methanol/EDTA-Mcllvaine solution $(1: 1, \mathrm{~V} / \mathrm{V})$ mixed solvent was used as the extraction solution, then ultrasonically extract was performed twice. The extract was diluted to $500 \mathrm{~mL}$ with $0.1 \%$ EDTA aqueous solution, and its $\mathrm{pH}$ was acidified to 4.0 at the same time for later use. SPE was treated with oasis hydrophilic lipophilic balance (HLB) column (6 mL / 200 mg, waters, Milford, Ma, USA), then it was activated with $5 \mathrm{~mL}$ methanol and $5 \mathrm{~mL}$ water respectively. The extract passed through HLB column at a flow rate of $<5 \mathrm{~mL} / \mathrm{min}$. The column was then washed with $3 \mathrm{~mL} 5 \%$ methanol and dried under vacuum for $0.5 \mathrm{~h}$, followed by elution with $10 \mathrm{~mL}$ methanol. The extract was concentrated and nearly dried under nitrogen atmosphere. Then, the target extracts were redissolved in methanol water $(1: 1, \mathrm{~V} / \mathrm{V})$ solution.

The sediment extract samples were analyzed through liquid chromatography with tandem mass spectrometry (LC-MS/MS), which were determined according to the procedures described in previous study (Tong et al., 2020). The samples were analyzed by liquid chromatography tandem mass spectrometry (LCMS/MS) using an Accela Max 600 high performance liquid chromatography system with an online degasser, quaternary solvent transport system, automatic sampler, TSQ Quantum Access Max (ESI) source and electrospray ionization source. A Hypersil Goldtm C18 (100 mm×2.1 mm,1.9 $\mu \mathrm{m}$, Thermofisher) was used at the flow rate of $0.3 \mathrm{~mL} / \mathrm{min}$ and the oven temperature was set at $40^{\circ} \mathrm{C}$. The mobile phase was consisted of water containing $0.1 \%(\mathrm{~V} / \mathrm{V})$ formic acid $(\mathrm{A})$ and methanol (B) with A gradual gradient distribution. Mass spectrometry was performed in positive ion mode, with sheath gas pressure of 40 bar, auxiliary gas pressure 
of $10 \mathrm{bar}$, carburetor temperature of $250^{\circ} \mathrm{C}$, capillary temperature of $350^{\circ} \mathrm{C}$ and capillary offset of 35 . Spray voltage is set to $+3800 \mathrm{~V}$. The analysis conditions for optimizing the MS/MS parameters (Du et al., 2017) are shown in Table S2. The recovery rate, limit of detection (LOD) and quantity (LOQ) were verified, and the results were shown in Table S3.

\subsection{Quantification of ARGs}

The sediment samples were sent to Shanghai Keyin Biological Technology (Shanghai, China) for analysis. Total DNA was extracted from $0.1 \mathrm{~g}$ fresh sediment samples by TIANNAMP Soil DNAKit (TIANGEN, China) following the manufacturer's protocols. The DNA extracted from sediment samples was stored below $-80^{\circ} \mathrm{C}$ for further analysis. The quality and concentration of the resultant DNA were determined by Quawell Q3000 spectrophotometer (Quawell Technology, USA).

The absolute abundance of two sul ARGs (sul1 and sul2), six tet ARGs (tetA, tetC, tetG, tetM, tetO and tetW), five qnr ARGs (qnrA, qnrC, qnrD, qnrS and aac (6') -IB), four erm ARGs (ermA, ermB, ermC and ermF), three $\beta$ endamide ARGs (blaTEM-1, blaOXA-1 and ampc), 16S and int11 was quantified by qPCR assays in sediment as previously described (Pu et al., 2017; Yang et al., 2018). The PCR product were detected and analyzed using a StepOnePlus ${ }^{\text {TW }}$ Realtime PCR(Thermo Fisher Scientific, Waltham, MA, USA). The primers for ARGs, correlation coefficients $\left(r^{2}\right)$ and standard curves of ARGs used in the study were shown in Table $S 4$ and Table S5.

\subsection{Environmental parameters in sediment}

Total carbon (TC), total organic carbon (TOC), total nitrogen (TN), total phosphorus (TP), total sulfur (TS) and heavy metals $(\mathrm{Zn}, \mathrm{Cr}, \mathrm{Ni}, \mathrm{Cu}, \mathrm{Pb}, \mathrm{As}, \mathrm{Cd}$ and $\mathrm{Hg}$ ) were determined in Baiyangdian Lake according to the Chinese standard geochemical sample analysis method (DZ/T 0279-2016).

\subsection{Statistical analysis}

Origin 2019 b and SPSS 26 software were used for statistical analysis of all data, linear regression was used for correlation analysis ( $P<0.05$ indicated significant differences), and redundancy analysis was conducted using the Canoco 5. Sampling sites were carried out by ArcMap10.6.

\section{Results}

\subsection{Basic physicochemical properties.}

The nutrients (TC, TOC, TN, TP and TS) and heavy metals ( $\mathrm{Zn}, \mathrm{Cr}, \mathrm{Ni}, \mathrm{Cu}, \mathrm{Pb}, \mathrm{As}, \mathrm{Cd}$ and $\mathrm{Hg}$ ) of the sediments in different habitats are summarized in Table S6. 16S and intl1 was quantified by qPCR assays in sediment. From Fig.S1, it can be seen that TC, TOC, TN and TS are highest in the open water (S10) because a lot of decaying aquatic plants were found in the water nearby when we sampled. In addition to the open water, the content of the nutrients (TC, TOC and TN) in the river estuaries are much higher than other habitats, which indicated that the river estuaries were received the sewage from Fuhe River and nearby villages. Meanwhile, the lowest levels of the nutrients (TC, TOC, TP and TN) and heavy metals ( $\mathrm{Cu}, \mathrm{Pb}, \mathrm{Ni}, \mathrm{As}, \mathrm{Cd}$ and $\mathrm{Hg}$ ) were found in the fish pond, which was different from what we expected, possibly due to the fact that the fish 
ponds have been continuously repaired or treated recently. The mean contents of heavy metals in six habitats were followed as the order from highest to lowest, the Fuhe River, the river estuaries, the living area, the open water, the fish poods and the reed marshes. The high content of heavy metals in Fuhe River and the river estuaries was closely related to the industrial wastewater in Baoding City.

For $16 \mathrm{~S}$ and int $11,16 \mathrm{~S}$ characterizes bacterial abundance and intl1 characterizes the level of gene migration (Hsu et al., 2014). As shown in Table.S8, the absolute abundance of $16 \mathrm{~S}$ in different aquatic areas ranged from $1.25 \times 10^{9}$ copies/g (S7) to $7.15 \times 10^{8}$ copies/g (S3), with an average absolute content of $1.05 \times 10^{9}$ copies/g. The absolute range of intl1 was $4.79 \times 10^{6} \mathrm{copies} / \mathrm{g}$ (S2) to 0 copies/g (S5, S6, S9), with an average absolute abundance of $1.03 \times 10^{6} \mathrm{copies} / \mathrm{g}$. The higher abundance of $16 \mathrm{~S}$ was found in open water, due to the decay of aquatic plants, which attract a large number of bacteria. And the lower abundance is concentrated in the reed marshes(S3), which was one tenth of that in the nearby estuary water (S2). The highest abundance of intl1 was found in the river estuarine, while the abundance of intl1 in the treated fish poods and reed marshes was almost undetectable. It is possible that the reduction of pollutants after sediment treatment or under the action of reeds marshes inhibited the level of gene migration.

\subsection{Occurrence of antibiotics in sediment}

Table 1, Table S7 and Fig. 2 summarizes the contents of all target antibiotic compounds in sediment samples from different waters area. More than 6 compounds tested were detected at $100 \%$ frequency in all samples in Baiyangdian Lake. The order of content of four kinds of antibiotics in different habitats was QNs, TCs, MLs, SAs. It can be seen that QNs are common and seriously polluted antibiotics in sediments of different habitats. CIP was detected at the highest levels in sediment samples of Baiyangdian Lake, and it reach up to $104.94 \mathrm{ng} / \mathrm{g}$. Obviously, the maximum contents of QNs are seriously higher than the other antibiotics, especially SAs.

Among the six different habitats, the maximum contents of antibiotics were found in river estuary, followed by fish poods, open water, Fuhe river, living area and reed marshes. The antibiotic content of the sediment dredged treatment (S6) or the demolished fish poods (S5) is significantly lower than that of the ecological restoration fish poods (S7, S8), and the lowest antibiotic content was found in the reed marshes (S9). Meanwhile, the antibiotic content in the reed marshes (S3) near the estuary was far lower than that in S2. Apparently, reeds have a significant removal effect on antibiotics.

Table.1 Antibiotic contents in different habitats from the aquaculture environment of Baiyangdian Lake 


\begin{tabular}{|lllllllllll|}
\hline \multicolumn{2}{|l}{ Sediment $(\mathbf{n}=\mathbf{1 0}, \mathbf{\mu g} / \mathbf{k g}$, dry/wt) } & & & & & & & \\
\hline Compounds & Min & Max & Mean & Fre/\% & Compounds & Min & Max & Mean & Fre/\% \\
\hline ERM- $\mathrm{H}_{2} \mathrm{O}$ & 0.04 & 1.04 & 0.20 & 100.00 & SQX & $<$ LOQ & 0.10 & 0.03 & 80.00 \\
\hline RTM & 0.04 & 2.41 & 0.32 & 100.00 & SDZ & $<$ LOQ & 0.10 & 0.03 & 90.00 \\
\hline CTM & 0.02 & 0.17 & 0.04 & 100.00 & SMX & $<$ LOQ & 0.12 & 0.04 & 70.00 \\
\hline AZM & $<$ LOQ & 0.22 & 0.04 & 80.00 & SMZ & $<$ LOQ & 0.68 & 0.11 & 90.00 \\
\hline TC & 0.11 & 2.25 & 0.25 & 100.00 & STZ & $<$ LOQ & $<$ LOQ & 0.00 & 0.00 \\
\hline DOC & $<$ LOQ & 2.14 & 0.20 & 90.00 & ENR & $<$ LOQ & 13.71 & 5.43 & 90.00 \\
\hline CTC & $<$ LOQ & 2.72 & 0.37 & 70.00 & SPA & $<$ LOQ & 0.07 & 0.02 & 50.00 \\
\hline OTC & $<$ LOQ & 31.03 & 1.42 & 90.00 & LOM & 0.05 & 0.24 & 0.10 & 100.00 \\
\hline SMR & $<$ LOQ & 0.10 & 0.01 & 70.00 & OFL & 1.96 & 11.99 & 4.88 & 100.00 \\
\hline SPD & $<$ LOQ & 0.64 & 0.01 & 50.00 & NOR & $<$ LOQ & 7.66 & 1.89 & 50.00 \\
\hline SMP & $<$ LOQ & 0.05 & 0.01 & 30.00 & CIP & $<$ LOQ & 104.94 & 12.18 & 20.00 \\
\hline a: Limits of quantification. & & & & & & & \\
\hline
\end{tabular}

\subsection{Occurrence of AGRs}

We detected 20 unique ARGs in all aquatic habitats, their relative abundance is shown in Fig. 3 and Table S8. Among all measured ARGs, the abundance of resistance genes was followed as the order, the sulfonamide resistance genes, quinolones resistance genes, macrolides, tetracycline resistance genes. Among the tested ARGs, sul1, sul2, aac(6')-IB, qnrA, qnrD, blaTEM-1, ermF, tetG and tetM had $100 \%$ detection rate frequencies in all typical habitats. Sul1 was present in high relative abundance $\left(6.21 \times 10^{7} \mathrm{copies} / \mathrm{g}\right)$ in all sediment samples, and the second was sul2 $\left(4.48 \times 10^{7} \mathrm{copies} / \mathrm{g}\right)$, which were significantly higher than the other resistance genes. Furthermore, aac(6')-IB $\left(1.01 \times 10^{6}-3.63 \times 10^{7} \mathrm{copies} / \mathrm{g}\right)$, as a qnr ARGs, the content was much higher than the other four qnr ARGs and the detection rate was found to be $100 \%$. In addition to sul ARGs and qnr ARGs, both tet ARGs and $\beta$-endamide ARGs were frequently detected in all habitats. While except for ermF $\left(5.13 \times 10^{3}-4.40 \times 10^{5}\right.$ copies $/ g, 100 \%$ detection rate), other three erm ARGs showed low detection frequencies $(40 \%-50 \%)$.

In terms of spatial distribution, the abundance of ARGs in different habitats of Nanliuzhuang were significantly higher than that of Caiputai. Meanwhile, the highest absolute abundance of ARGs were mainly concentrated near the Fuhe river (S1) and the river estuary (S2), and the lower value was mainly in fish poods(S6-S8) and reed marshes(S9). In the case of fish poods, the absolute abundance of the total ARGs in the fish poods (S6) was $6.02 \times 10^{7}$ copies $/ \mathrm{g}$, which was much lower than that of the dredged and bioremediation ponds. Moreover, compared with two points (S3 and S9) in reed marshes, the total absolute abundance of ARGs in the sample point (S3) were significantly higher than the other (S9). 


\subsection{Impact of environmental factors on the absolute abundance of ARGs}

Pearson correlation coefficients were calculated to examine the correlations between ARGs concentrations in different functional area of sediments (Table S9), the concentrations of TP and six ARGs had significant positive correlations ( $\mathrm{p}<0.05)$. Heavy metals $(\mathrm{Cu}, \mathrm{Pb}, \mathrm{Zn}, \mathrm{Cr}, \mathrm{Ni}, \mathrm{Cd}$ and $\mathrm{Hg}$ ) and nine ARGs (ermB, ermF, sul1, sul2, tetA, tetG, tetM, blaOXA-1 and aac $\left.\left(6^{\prime}\right)-I B\right)(p<0.05)$ exhibited significantly positive correlation. SAs and MLs appeared significant negatively correlated to sul1 $(p<0.01)$, sul2 ( $<<0.01)$, and tetO $(p<0.01)$, while QNs showed significant positive correlation with ermC $(p<0.05)$, sul1 $(p<0.05)$, and tetO $(p<0.01)$. Furthermore, intl1 showed significant positive correlation with blaOXA-1 $(p<0.05)$, ermC $(p<0.01)$, sul1 $(p<0.01)$, sul2 $(p<0.01)$, tetM $(p<0.05)$, tetO $(p<0.01)$.

In this study, Redundancy analysis (RDA) was used to explain the relationship between basic physicochemical properties and ARGs in the six habitats. According to RDA (Fig. 4), ARGs are not only related to antibiotics, heavy metals and nutrients, but also related to each other respectively. Redundancy analysis further confirmed the correlation analysis results among $\mathrm{Cu}, \mathrm{Zn}$, intl1, TP, MLs and ARGs.

\section{Discussion}

\subsection{Presence of antibiotics in different habitats}

Compared with SAs, MLs and TCs, QNs had the highest content in the sediments of different habitats in Baiyangdian Lake. This could result from their high viscosity leading to difficult to biodegrade, which promotes their persistence in the sediments (Moerno-Bondi et al., 2009). Meanwhile, the sorption coefficient of QNs was much higher than that of other antibiotics, which described the reversible adsorption and exchange of chemicals between water and sediment (Yang et al., 2010). The larger the sorption coefficient was, the stronger the chelating ability of the sediments was obtained with particles and cations (Li et al., 2012). Therefore, it is difficult to degrade and even accumulate in the sediments.

For all antibiotics tested, QNs were detected in all habitats in sediment samples, with the exception of certain low-frequency compounds such as CIP and NOR, which were almost absent in fish poods and reed marshes. This may be due to its low mobility in fish poods or reed marshes (Tong et al., 2020). The highest level of total antibiotics was found in the river estuary (S2) near the Fuhe river (S1), while the lowest level was found in reed marshes (S10), where water was constantly purified by the reeds around it. In the same way, the total amount of antibiotics in reed marshes (S3) near the estuary was significantly lower than that in the estuary river (S2). Besides, compared with the biological treatment fish poods (S7 and S8), the total amount of antibiotics in the dredged (S6) or merged into rivers (S5) decreased significantly. These results show that bioremediation may not effectively and quickly reduce the antibiotics in the surface sediments of fish ponds, and dredging or flowing into rivers can transfer antibiotics to achieve the purpose of less pollutants.

\subsection{Diversity and abundance of ARGs}


In this study, the ARGs were detected in different habitats of Baiyangdian Lake, which indicated that antibiotic resistance genes had been widespread in Baiyangdian Lake environment. Previous study (Chen et al., 2020) also indicated that abundant resistance genes were detected in the sediments of Baiyangdian Lake, leading to the high risk, and $80 \%$ ARGs were introduced from Fuhe River into Baiyangdian Lake. The risk of ARGs was higher than many lakes in Baiyangdian Lake, which was polluted by urban sewage, domestic sewage and aquaculture sewage (Chen et al., 2020; Zhang et al., 2020a). In this study, we also observed similar contents of ARGs in the Fuhe river and estuarine water. Apparently, the high detection rate and high absolute abundance of ARGs in estuarine water may be related to various pollution sources and human activities.

Sul ARGs are usually dominant among ARGs found in many sediments. Among all measured ARGs, the absolute abundance of sul 1 was the highest, which is mobile DNA element-borne resistance gene, parallel transferring between bacterial populations and species (Hsu et al., 2014). The absolute abundance of sul2 is second only to sul1, which is similar to that of intl1, and its high abundance is closely related to intl. For example, a significant correlation between sul ARGs and intl1 was found, and the contribution rate of Sul ARGs was the highest in the environment in Japan (Partridge et al., 2015) and China (Suzuki et al., 2019). In addition to sul1 and sul2, the absolute abundance of aac(6')-IB in qnr ARGS range was between $1.01 \times 10^{6}$ copies/g and $3.63 \times 10^{7}$ copies/g, and the detection rate was $100 \%$. The distribution characteristics of this gene showed that the absolute abundance in the habitat near the Fuhe River and the estuaries river was one order of magnitude higher than that in other habitats, which might be related to the continuous input of industrial wastewater from the Fuhe River (Chen et al., 2010). Furthermore, although all the 13 erm ARGs, tet ARGS and $\beta$-endamide ARGs were detected in varying degrees, most of them did not have high absolute abundance. This may be related to their long persistence and not easy to disappear in the aquatic environment (Guo et al., 2018).

\subsection{Factors influencing the ARG distribution}

In the present study, ARGs in the main habitats positively correlated with the environmental factors. However, it was still difficult to explain the transmission of ARGs in different habitats of aquatic environments. Under the joint analysis of correlation analysis and RDA, the results showed that $\mathrm{Cu}, \mathrm{Zn}$, intl1, TP and MLs affected the absolute abundance of ARGs in different habitats of Baiyangdian Lake. This result is basically consistent with previous studies, which is showed that HMs promote the transfer of ARGs in the environment through the formation of reactive oxygen species, the increase of membrane permeability, the change of SOS response and the expression of conjugation related genes (Sun et al., 2021; Mckinney et al., 2010).

Particularly, it is widely accepted that when the concentration of antibiotics is higher than the background, the bacteria will become resistant bacteria through mutation or accelerated acquisition of exogenous resistance. At the same time, a large number of studies have shown that the abundance of surface resistance genes is positively correlated with antibiotics (Tong et al., 2020). Furthermore, in terms of the nutrients, TP is mainly related to ARGs. Previous studies found that the nutrients (TP) can affect microbial diversity and was one of the key factors of bacterial community structure change in Baiyangdian Lake (Zhang et al., 2020a; Leng et al., 2020). The influencing factors of ARGs in the mono-habitat lakes are still related to antibiotics, HMs, nutrients and integrons, while the mono-habitat lakes are often affected by heavy 
metal or antibiotic pressure (Zhou et al., 2019; Tong et al., 2020; Zhao et al.,2020). Therefore, due to the complex habitat of Baiyangdian Lake and the human activities result in the input of ARGs into lakes through Fuhe River, these results indicated that there are some differences in the influencing factors of resistance genes between the multi-habitat lakes and mono-habitat lakes. On the whole, it is proved that these environmental factors play a certain role in the spread of ARGs. Therefore, it is necessary to discuss the propagation mechanism and risk assessment method of ARGs.

\section{Conclusions}

In summary, the study represented the occurrence of antibiotics and ARGs in Fuhe river, the estuaries river, the reed marshes, the living area, the fish poods, and the open water of Baiyangdian Lake. QNs were dominant among the antibiotics, especially in the river entrance habitat, and the highest content is up to $104.94 \mathrm{ng} / \mathrm{g}$. The 20 kinds of ARGs, intl1 and $16 \mathrm{~S}$ have been detected with varying degrees in different habitats, indicating that Baiyangdian Lake is an important reservoir of ARGs. Thereinto, sul1 had the highest absolute abundance $\left(6.21 \times 10^{7}\right.$ copies $\left./ \mathrm{g}\right)$, which was mobile DNA element-borne resistance gene.

Furthermore, redundant analysis showed that $\mathrm{Cu}, \mathrm{Zn}$, intI1, TP and MLs were important factors affecting the abundance and distribution of ARGs in the sediments of different habitats of Baiyangdian Lake. Given this situation, it is necessary to further study the synergistic effect of antibiotics and heavy metals on the source and fate of resistance genes, as well as the potential harm to human beings.

\section{Declarations}

Author contribution All authors contributed to the study conception and design. Guiying Liao gave the idea of this research work. Material preparation, data collection, and analysis were performed by Tongfei Wang. The first draft of the manuscript was written by Guiying Liao and Tongfei Wang. Meiyi Zhang, Liqing Li, Weijun Zhang and Dongsheng Wang helped the work with his ideas and made a critical editing and reviewing of the whole manuscript. All authors read and approved the final manuscript.

Funding This work was supported by the Major Science and Technology Program for Water Pollution Control and Treatment (2018ZX07110004).

Availability of data and materials Not applicable.

\section{Declarations}

Ethics approval Not applicable.

Consent to participate Not applicable.

Consent for publication Not applicable.

Competing Interests The authors declare no competing interests.

\section{References}


Amarasiri M, Sano D, Suzuki S (2020) Understanding human health risks caused by antibiotic resistant bacteria (ARB) and antibiotic resistance genes (ARG) in water environments: Current knowledge and questions to be answered. Crit Rev Environ Sci Technol 50:2016-2059.

Chen H Y, Jing L J, Teng Y G, Wang J S (2018) Characterization of antibiotics in a large-scale river system of China: Occurrence pattern, spatiotemporal distribution and environmental risks. Sci Total Environ 618:409418.

Chen H Y, Jing L J, Yao Z P, Meng F S, Teng Y G (2019a) Prevalence, source and risk of antibiotic resistance genes in the sediments of Lake Tai (China) deciphered by metagenomic assembly: A comparison with other global lakes. Environ Int 127:267-275.

Chen H Y, Li Y Z, Sun W C, Song L T, Zuo R, Teng Y G (2020) Characterization and source identification of antibiotic resistance genes in the sediments of an interconnected river-lake system. Environ Int 137:105538.

Chen J, Wu J L, Liu M, Li L Q, Zhang W J, Wang D L, Ma T (2021) Bacterial community structure in the surface sediments of different habitats of Baiyangdian Lake, Northern China: effects of nutrient conditions. J Soils Sed 21:1866-1874.

Chen J Y, Su Z G, Dai T J, Huang B, Mu Y M, Zhang Y M, Wen D H (2019b). Occurrence and distribution of antibiotic resistance genes in the sediments of the East China Sea bays. J Environ Sci (China) 81:156-167.

Chen K, Zhou J L (2014). Occurrence and behavior of antibiotics in water and sediments from the Huangpu River, Shanghai, China. Chemosphere 95:604-612.

Cheng D M, Liu X H, Liang W, Gong W W, Liu G N, Fu W J, Cheng M (2014a). Seasonal variation and sediment-water exchange of antibiotics in a shallower large lake in North China. Sci Total Environ 476-477, 266-275.

Cheng M, Wu L, Huang Y, Luo Y, Christie P (2014b) Total concentrations of heavy metals and occurrence of antibiotics in sewage sludges from cities throughout China. J Soils Sed 14:1123-1135.

Czekalski N, Sigdel R, Birtel J, Matthews B, Buergmann H (2015). Does human activity impact the natural antibiotic resistance background? abundance of antibiotic resistance genes in 21 swiss lakes. Environ Int 81: 45-55.

Du J, Zhang H X, Liu S S, Xie H J, Wang Y, Chen J W. (2017) Antibiotics in the coastal water of the South Yellow Sea in China: Occurrence, distribution and ecological risks. Sci Total Environ 595:521-527.

Gillings M R, Gaze W H, Pruden A, Smalla K, Tiedje J M, Zhu Y G (2015) Using the class 1 integron-integrase gene as a proxy for anthropogenic pollution. ISME J 9:1269-1279.

Gulkowska A, Leung H W, So M K, Taniyasu S, Yamashita N, Yeunq L W Y, Richardson, B.J., Lei, A.P., Giesy, J.P. and Lam, P.K.S. (2008) Removal of antibiotics from wastewater by sewage treatment facilities in Hong Kong and Shenzhen, China. Water Res 42:395-403. 
Guo X P, Liu X R, Niu Z.S, Lu D P, Zhao S, Sun X L, Wu J Y, Chen Y R, Tou F Y, Hou L,J, Liu M, Yang Y (2018) Seasonal and spatial distribution of antibiotic resistance genes in the sediments along the Yangtze Estuary, China. Environ Pollut 242:576-584.

Han X M, Hu H W, Shi X Z, Wang J T, Han L L, Chen D L, He J Z (2016) Impacts of reclaimed water irrigation on soil antibiotic resistome in urban parks of Victoria, Australia. Environ Pollut 211:48-57.

Hsu J T, Chen C Y, Young C W, Chao W L, Li M H, Liu Y H, Lin C M, Ying C W (2014) Prevalence of sulfonamide-resistant bacteria, resistance genes and integron-associated horizontal gene transfer in natural water bodies and soils adjacent to a swine feedlot in northern Taiwan. J Hazard Mater 277:34-43.

Ji Z H, Zhang H, Zhang Y, Chen T, Long Z W, Li M, Pei Y S (2019) Distribution, ecological risk and source identification of heavy metals in sediments from the Baiyangdian Lake, Northern China. Chemosphere 237:124425.

Kim J H, Kuppusamy S, Kim S Y, Kim S C, Kim H T, Lee Y B (2017) Occurrence of sulfonamide class of antibiotics resistance in Korean paddy soils under long-term fertilization practices. J Soils Sed 17:16181625.

Klein E Y, Van Boeckel T P, Martinez E M, Pant S, Gandra S, Levin S A, Goossens H, Laxminarayan R (2018) Global increase and geographic convergence in antibiotic consumption between 2000 and 2015. Proc Natl Acad Sci U S A 115: 3463-3470.

Knapp C W, Dolfing J, Ehlert P A I, Graham D W (2010) Evidence of increasing antibiotic resistance gene abundances in archived soils since 1940. Environ Sci Technol 44:580-587.

Kummerer K (2009) Antibiotics in the aquatic environment - A review - Part I. Chemosphere 75:417-434.

Larson E (2007) Community factors in the development of antibiotic resistance. Annu Rev Public Health 28:435-447.

Leng Y F, Xiao H L, Li Z, Wang J (2020) Tetracyclines, sulfonamides and quinolones and their corresponding resistance genes in coastal areas of Beibu Gulf, China. Sci Total Environ 714:136899.1-136899.9.

Li A L, Chen L J, Zhan, Y, Tao Y L, Xie H, Li S, Sun W L, Pan J G, He Z D, Mai C A, Fan Y Y, Xian H C, Zhang Z B, Wen D H. (2018a). Occurrence and distribution of antibiotic resistance genes in the sediments of drinking water sources, urban rivers, and coastal areas in Zhuhai, China. Environ. Sci Pollut Res, 25(26), 26209.

Li J, Cao J J, Zhu Y G, Chen Q L, Shen F X, Wu Y, Xu S Y, Fan H, Da G, Huang R J, Wang J, de Jesus A L, Morawska L, Chan C K, Peccia J, Yao M S (2018b) Global Survey of Antibiotic Resistance Genes in Air. Environ Sci Technol 52:10975-10984.

Li W H, Shi Y L, Gao L H, Liu J M, Cai Y Q (2012) Occurrence of antibiotics in water, sediments, aquatic plants, and animals from Baiyangdian Lake in North China. Chemosphere 89:1307-1315. 
Liu X H, Zhang G D, Liu Y, Lu SY, Qin P, Guo X C, Bi B, Wang L, Xi B D, Wu F C, Wang W L, Zhang T T (2019) Occurrence and fate of antibiotics and antibiotic resistance genes in typical urban water of Beijing, China. Environ Pollut 246:163-173.

Luo Y, Mao D Q, Rysz M, Zhou D X, Zhang H J, Xu L, Alvarez P J J (2010) Trends in Antibiotic Resistance Genes Occurrence in the Haihe River, China. Environ Sci Technol 44:7220-7225.

Mccann C M, Christgen B, Roberts J A, Su J Q, Arnold K E, Gray N D, Zhu Y G, Graham D W (2019) Understanding drivers of antibiotic resistance genes in High Arctic soil ecosystems. Environ Int 125:497-504.

McKinney C W, Loftin K A, Meyer M T, Davis J G, Pruden A (2010) tet and sul antibiotic resistance genes in livestock lagoons of various operation type, configuration, and antibiotic occurrence. Environ Sci Technol 44:6102-6109.

Moreno-Bondi M C, Marazuela M D, Herranz S, Rodriguez E (2009) An overview of sample preparation procedures for LC-MS multiclass antibiotic determination in environmental and food samples. Anal Bioanal Chem 395:921-946.

Muhammad J, Khan S, Su J Q, Hesham A E-L, Ditta A, Nawab J, Ali A (2020) Antibiotics in poultry manure and their associated health issues: a systematic review. J Soils Sed 20:486-497.

Nguyen T N, Kasuga I, Liu M, Katayama H (2019). Occurrence of antibiotic resistance genes as emerging contaminants in watersheds of tama river and lake kasumigaura in japan. Energy Environ Sci 266: 1200312012.

Partridge S R, Tsafnat G, Coiera E, Iredell J R (2009) Gene cassettes and cassette arrays in mobile resistance integrons. FEMS Microbiol Rev 33:757-784.

Paulus, G.K., Hornstra, L.M. and Medema, G. (2020) International tempo-spatial study of antibiotic resistance genes across the Rhine river using newly developed multiplex qPCR assays. Sci Total Environ 706:135733.

Pruden A, Arabi M, Storteboom H N (2012) Correlation Between Upstream Human Activities and Riverine Antibiotic Resistance Genes. Environ Sci Technol 46:11541-11549.

Pu C J, Liu H, Ding G C, Sun Y, Yu X L, Chen J H, Ren J Y, Gong X Y (2018) Impact of direct application of biogas slurry and residue in fields: In situ analysis of antibiotic resistance genes from pig manure to fields. $J$ Hazard Mater 344:441-449.

Quaik S, Embrandiri A, Ravindran B, Hossain K, Al-Dhabi N A, Arasu M V, Ignacimuthu S, Ismail N (2020) Veterinary antibiotics in animal manure and manure laden soil: Scenario and challenges in Asian countries. J King Saud Univ Sci 32:1300-1305.

Reichert G, Hilgert S, Alexander J, de Azevedo J C R, Morck T, Fuchs S, Schwartz T (2021) Determination of antibiotic resistance genes in a WWTP-impacted river in surface water, sediment, and biofilm: Influence of seasonality and water quality. Sci Total Environ 768:144526-144535. 
Sun F L, Xu Z T, Fan L L (2021). Response of heavy metal and antibiotic resistance genes and related microorganisms to different heavy metals in activated sludge. J Environ. Manage 300,113754.

Suzuki S, Nakanishi S, Tamminen M, Yokokawa T, Sato-Takabe Y, Ohta K, Chou H Y, Muziasari W I, Virta M (2019). Occurrence of sul and tet $(\mathrm{m})$ genes in bacterial community in Japanese marine aquaculture environment throughout the year: profile compari-son with taiwanese and finnish aquaculture waters. Sci Total Environ 669(15), 649-656.

Tong L, Qin L T, Guan C, Wilson M E, Li X J, Cheng D D, Ma J, Liu H, Gong F J (2020) Antibiotic resistance gene profiling in response to antibiotic usage and environmental factors in the surface water and groundwater of Honghu Lake, China. Environ. Sci Pollut Res 27:31995-32005.

Yang J F, Ying G G, Zhao J L, Tao R, Su H C, Chen F (2010) Simultaneous determination of four classes of antibiotics in sediments of the Pearl Rivers using RRLC-MS/MS. Sci Total Environ 408:3424-3432.

Yang W, Yan J, Wang Y, Zhang B T, Wang H J (2020) Seasonal variation of aquatic macrophytes and its relationship with environmental factors in Baiyangdian Lake, China. Sci Total Environ 708: 135112.

Yang X L, Zhang S, Li H, Zhang L M, Song H L,Wang Y W (2018) Effects of voltage on sulfadiazine degradation and the response of sul genes and microbial communities in biofilm-electrode reactors. Ecotoxicol Environ Saf 151:272-278.

Yang Y Y, Liu W Z, Xu C, Wei B Q, Wang J (2017) Antibiotic resistance genes in lakes from middle and lower reaches of the Yangtze River, China: Effect of land use and sediment characteristics. Chemosphere 178:1925.

Zerizghi T, Yang Y F, Wang W J, Zhou Y, Zhang J, Yi Y J (2020) Ecological risk assessment of heavy metal concentrations in sediment and fish of a shallow lake: a case study of Baiyangdian Lake, North China. Environ Monit Assess 192(2):154.1-154.16.

Zhang L L, Shen L A, Ju Z J, Fu Y, Qin S, Cui J S (2020a) The key environmental influencing factors for the change of sediment bacterial community and antibiotics resistance genes in a long-term polluted lake, China. Ecotoxicology.

Zhang Q Q, Ying G G, Pan C G, Liu Y S, Zhao J L (2015) Comprehensive evaluation of antibiotics emission and fate in the river basins of China: source analysis, multimedia modeling, and linkage to bacterial resistance. Environ Sci Technol 49:6772-6782.

Zhang T Q, Lu K Y, Lu Q X, Wang L L, Liu X W (2021). Removal of antibiotic-resistant genes during drinking water treatment: A review. J Environ Sci (China) 104:415-429.

Zhang Y X, Chen H Y, Jing L J, Teng Y G (2020b) Ecotoxicological risk assessment and source apportionment of antibiotics in the waters and sediments of a peri-urban river. Sci Total Environ 731:139128139137. 
Zhao B, Xu J M, Zhang G D, Lu S Y, Liu X H, Li L X, Li M (2021) Occurrence of antibiotics and antibiotic resistance genes in the Fuxian Lake and antibiotic source analysis based on principal component analysismultiple linear regression model. Chemosphere 262.

Zhao J L, Liu Y S, Liu W R, Jiang Y X, Su H C, Zhang Q Q, Chen X W, Yang Y Y, Chen J, Liu S S, Pan C G, Huang G Y, Ying G G (2015) Tissue-specific bioaccumulation of human and veterinary antibiotics in bile, plasma, liver and muscle tissues of wild fish from a highly urbanized region. Environ Pollut 198:15-24.

Zheng J, Zhou Z C, Wei Y Y, Chen T, Feng W Q, Chen H (2018) High-throughput profiling of seasonal variations of antibiotic resistance gene transport in a peri-urban river. Environ Int 114:87-94.

Zhou Q, Wang M Z, Zhong X X, Liu P, Xie X Y, Wangxiao J Y, Sun Y X. (2019). Dissemination of resistance genes in duck/fish polyculture ponds in guangdong province: correlations between cu and zn and antibiotic resistance genes. Environ. Sci Pollut Res 26: 8182-8193.

Zhu Y G, Johnson T A, Su J Q, Qiao M, Guo G X, Stedtfeld R D, Hashsham S A, Tiedje J M (2013) Diverse and abundant antibiotic resistance genes in Chinese swine farms. Proc Natl Acad Sci U.S.A 110:3435-3440.

Zhu Y, Miao J R, Wen H X, Li T H X, Zhao Z H, Guo X, Li H, Zhang G X (2020) The occurrence and spatial distribution of typical antibiotics in soils along the Fenhe River in Shanxi Province. J Soils Sed 20:889-899.

\section{Figures}
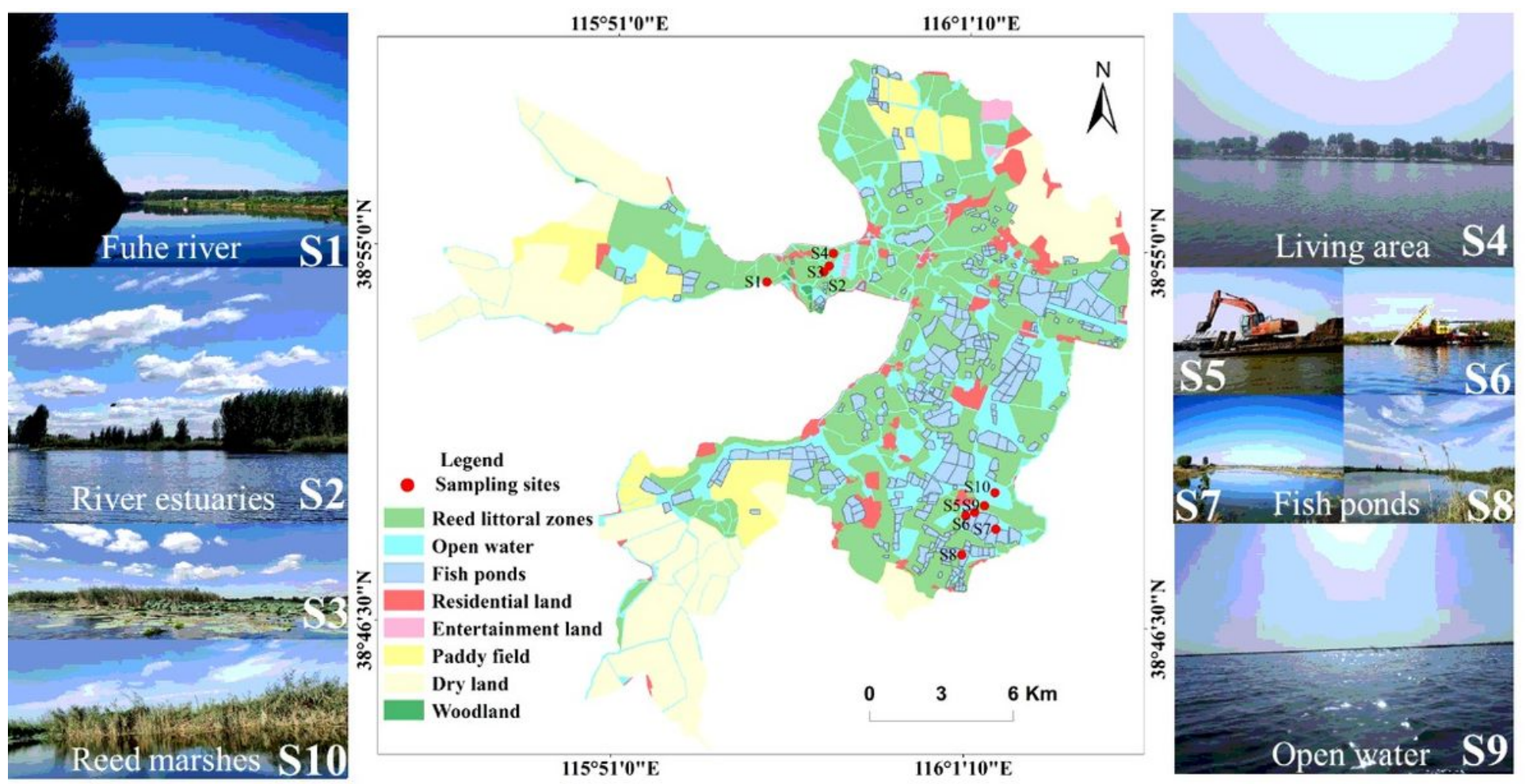

Figure 1 


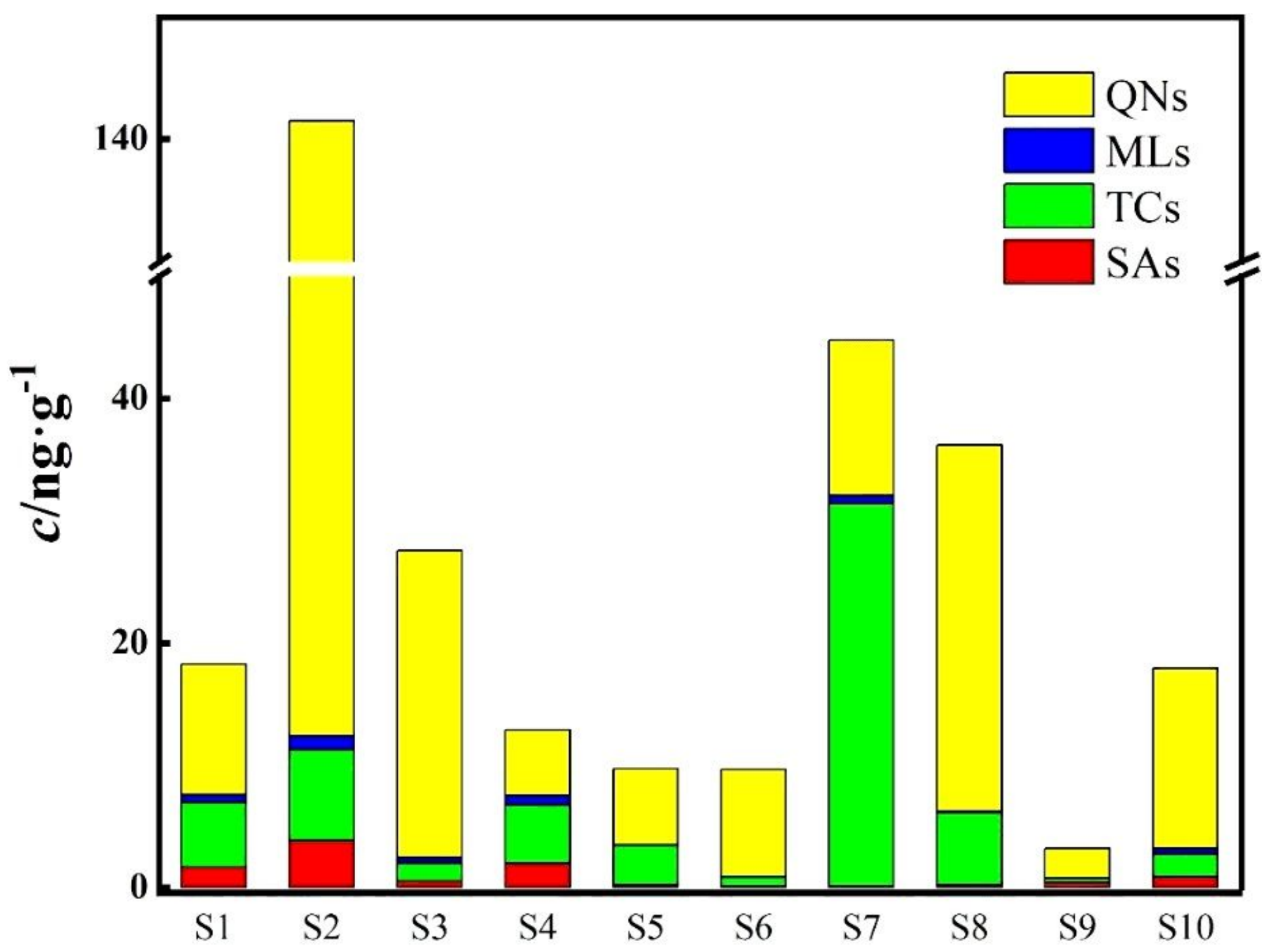

Figure 2

Contents of QNs, MLs, TCs and SAs 


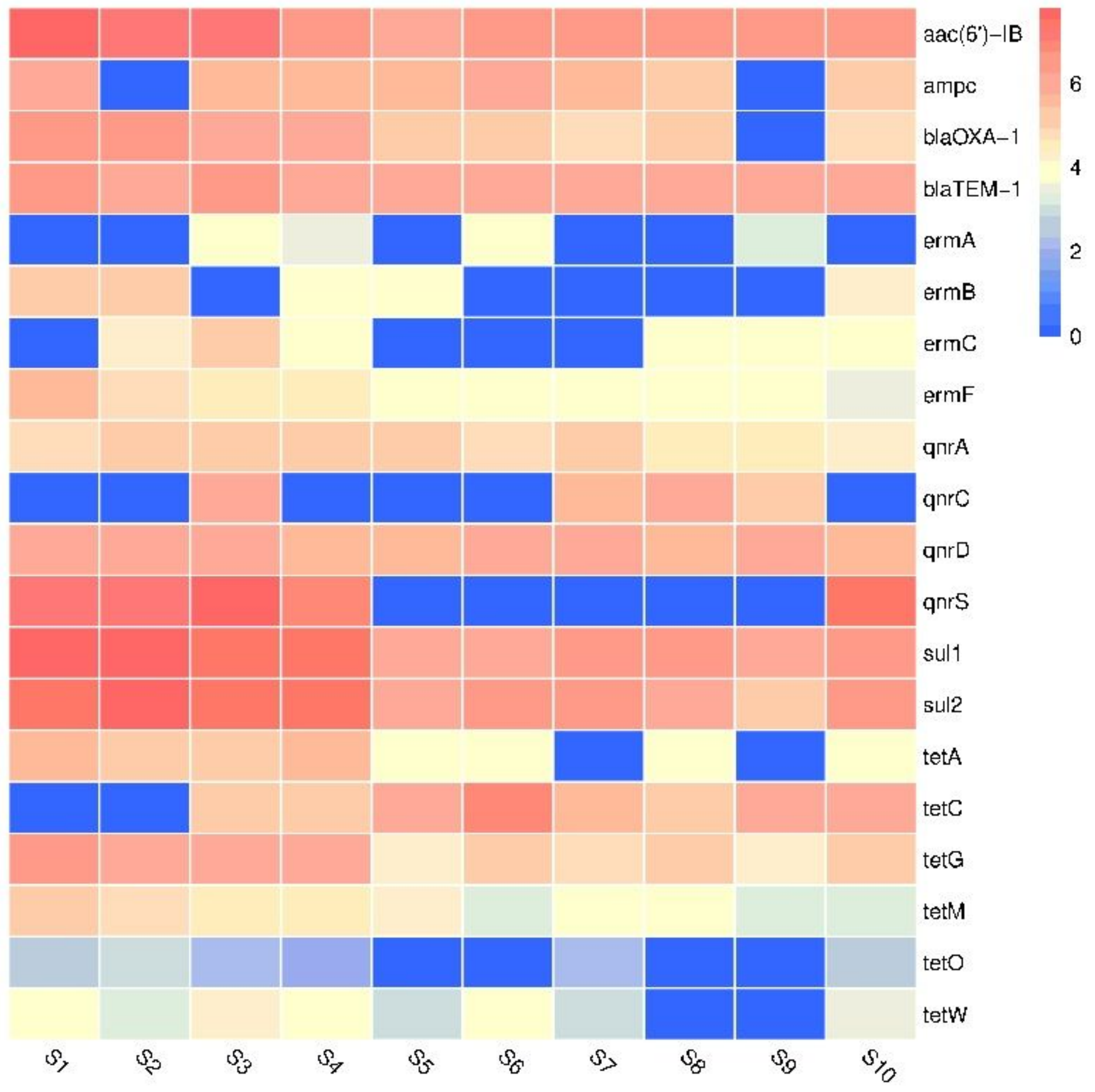

Figure 3

Heat map of ARGs 

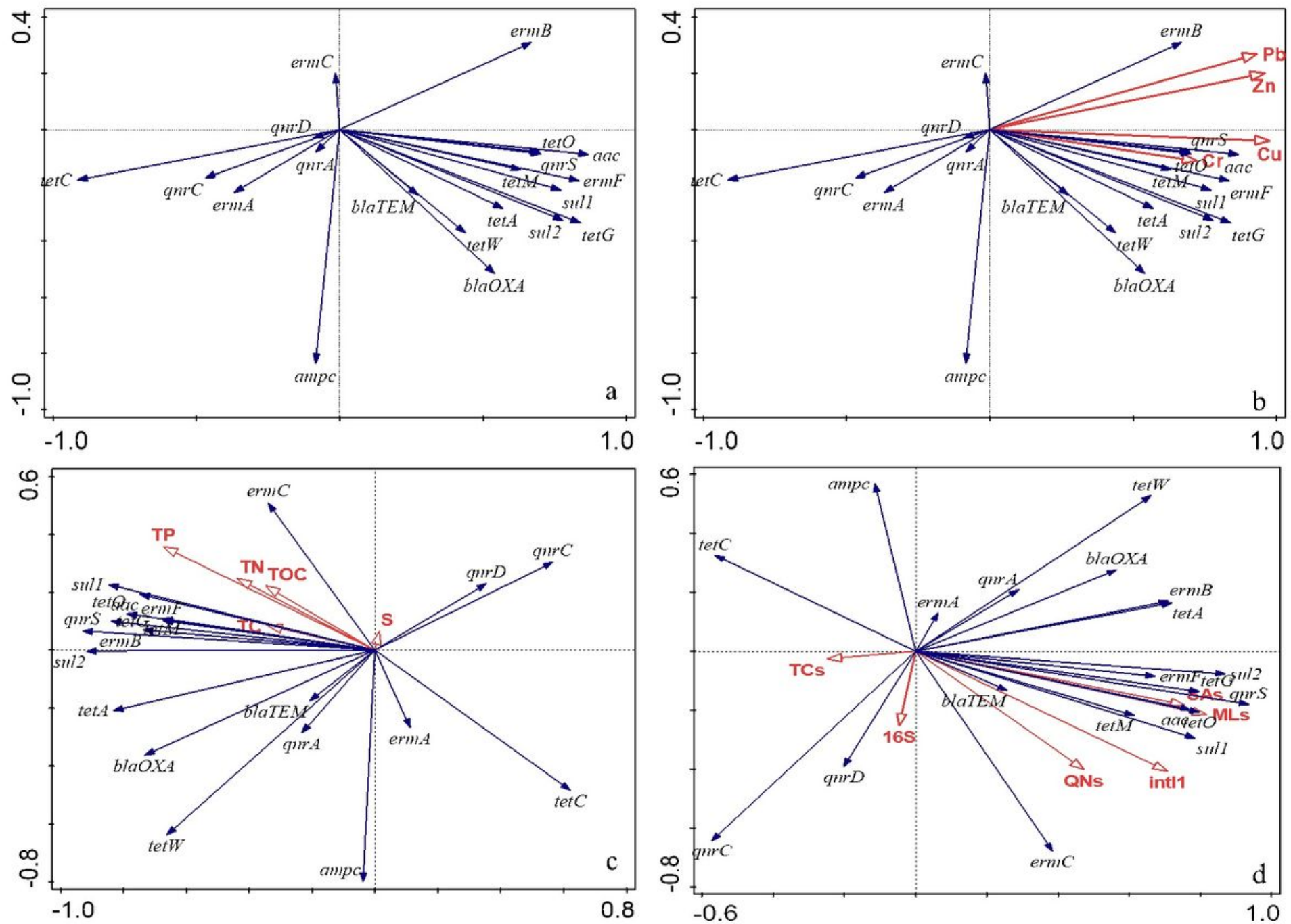

\section{Figure 4}

Redundancy analysis (RDA) between basic physicochemical properties and ARGs in sediments, indicates the interrelationship between ARGs and environmental variables ARGs are enclosed; a ARGs, b heavy metals (Zn, $\mathrm{Cr}, \mathrm{Cu}$ and $\mathrm{Pb}$ ), c nutrients (TC, TOC, TN, TP and TS), d antibiotics, intl1 and $16 \mathrm{~S}$.

\section{Supplementary Files}

This is a list of supplementary files associated with this preprint. Click to download.

- Supplementarymaterialof.docx 